Canadian Journal of Family and Youth, 14(2), 2022, pp. 177-181

ISSN 1718-9748@ University of Alberta

http://ejournals,library,ualberta.ca/index/php/cify

\title{
Barkin, Janna. (2017). He's Always Been My Son: A Mother's Story About Raising Her Transgender Son. London: Jessica Kingsley Publishers.
}

Reviewed by: Hanna Clarke, MacEwan University

Janna Barkin's book “He’s Always Been My Son”, recounts the experiences Janna Barkin and her family endured in raising their transgender child, Amaya. Barkin reveals the realities of having a transgender child and lays a compassionate and informative ground for people navigating similar journeys. The book shows how it truly does take a village to raise a child - especially a thriving gender creative one - with additional chapter contributions from family members and loved ones about their experiences supporting Amaya through his transition. The book contains valuable resources for those figuring out how to support a transgender child in the way they need.

Barkin's story uncovers some of the challenges and realities Transgender individuals and their families face in society. Things are improving beyond a doubt, but statistics show that we still have so much work to do. It is not a secret that Transgender individuals face increased levels of victimization, mental health problems and suicide rates. Barkin fully acknowledges this dark truth, revealing the shocking statistic that "Lesbian, Gay, Bisexual, Transgender, Queer or Questioning (LGBTQ) youth have among the highest suicide rates in the nation. While more studies are needed, currently it is believed that at least 25 percent of transgender youth have attempted suicide, and rates as high as 41 percent have been cited" (p. 14). Barkin also stresses the importance of having a supportive environment for transgender youth to explore their identity. In 
a study of 10,000 LGBTQ youth, the results found that "forty two percent said that the community in which they live is not accepting of LGBT people; twenty six percent said their biggest problems were "not feeling accepted by their family/trouble at school/bullying," and "fear to be out/open" (p. 14). The reality is that many transgender youths do not get the same level of acceptance that Amaya was blessed with- and Barkin acknowledges this privilege. She states that "having the support of family is the number one way to prevent depression and suicide among transgender youth" (p. 82). Another direct harm that Transgender individuals face that Barkin teaches us is in misgendering- from the harmless use of wrong pronouns to intentional misgendering. Barkin supported her child completely and unconditionally and protected him from many of the harms that a lot of other Transgender individuals face by being a strong advocate with an open mind and heart. If this was the same for all parents of a Transgender or gender-questioning youth, those previous statistics would drop dramatically, and the world would be a safer place for Transgender individuals.

A key part of the foundation of the book is distinguishing the difference between gender identity and gender expression and Barkin shows the importance of both in Transgender individuals. Barkin defines gender expression as "the way one presents to the outside world. This includes choices in clothes, style, hair, activities, communication style" and gender identity as "a person's deeply felt inner sense of who they are " (p. 18). Barkin teaches us that a child can start showing differing gender expressions from a very young age- maybe even before they are able to talk. For Amaya, Barkin recounts that he was about three years old when he started making his own choices regarding what he wore, the way he acted and his hobbies. Jean Piaget defines this as 
the "formation of self-identity phase" (p. 52). Barkin's story shows that in some cases- like Amaya's, individuals decide to express themselves outwardly which aligns with their gender identity, before making an actual transition. A chapter contribution from Amaya's paternal grandmother touches on Amaya's gender expression around age four to five, where he confidently picked out a large toy Ford F-150 pickup truck for his toy of choice. Another chapter contribution from Amaya's maternal grandmother notes how his preferences were wildly different from his sister Emily's- showing how from a young age he started to "show a preference for coveralls, jeans, trucks, nothing with ruffles or bright colours, no skirts or tights, no angel wigs" (pp. 256257).

Unfortunately, gender dysphoria is another familiar experience for Transgender individuals. Barkin defines gender dysphoria as "a profound, persistent state of unease or dissatisfaction, anxiety, or depression that occurs when an individuals' internal sense of who they are does not align with the sex assigned at birth" (p. 22). Gender dysphoria is experienced by different people, in different ways, at different times in their journey. It might feel like anger or sadness, feeling negative about your body or like there are "parts" of you missing. Barkin talks about how her son Amaya started binding his chest in order to reduce his gender dysphoria- a common tactic for Transgender men and non-binary individuals. She also educates readers on the modern use of puberty blockers- something not commonly talked about but a huge resource to transgender people- especially those facing dysphoria usually aggravated by going through puberty. Puberty blockers allows a child "time to explore and understand their gender identity and allows them to undergo puberty in a manner that best aligns with their gender identity" (p. 85). 
This is an amazing resource for today's transgender youth, and I believe the book does am efficient job of informing people of how crucial they can be in reducing gender dysphoria that the development of unwanted body parts and other features can cause transgender individuals.

Above all, this book focuses on being a guide for Transgender individuals and their families. Barkin walks individuals through the different phases of a transgender individual's transition. Transition starts in the before years, where there is no difference between gender identity or expression regarding sex. Next comes the early years, where children might start to show some differing gender expression. The tween years are those between early and actual transition and is a more confusing stage for transgender individuals and their families. There is definitely incongruence, but nothing is really clear for either the child or the parents at this point. This is the stage where individuals might explore their identity more through experimentation. Transition years is where there is a real shift, and an individual begins to affirm their gender identity and want to live as so. Finally, there is the complete stage- which might not actually be complete. The complete stage is only determined by whether that person feels fully fulfilled in their gender identity and expression. Regarding transition, Barkin walks families through processes of securing medical coverage for gender transition related surgery and legal document changes- as neither are proved to be easy processes. Barkin's book is filled with resourcesacademic and personal. She not only provides a full glossary to stress the importance of using appropriate words to identify ourselves and others- but even provides a full resource list at the end of the book where transgender individuals and their families can seek out support.

Barkin's intentions when writing the book were to provide insight into what it is like to parent a transgender child, along with the many challenges they face and how to navigate such 
challenges. She shares her personal story to not only help others, but to show that with compassion, empathy, support, and love- transgender children can thrive. I personally didn't see very many limitations with the book. I think for its purpose, it did the job. It provided personal experiences, stories from supporting people in Amaya's life, resources for others, and addressed many of the realities that transgender people and their families live with. It was simple yet very informative. I believe the type of academic audience that would be interested in reading this book would be people in the Sociology discipline, Social Work, Child and Youth Care, Health Care, Therapists and Counsellors- anybody that would work with potential gender questioning youth to provide the support they so desperately deserve and need. In the larger sense, I would recommend this book to everyone and anyone. I believe the knowledge and purpose behind it is unmeasurable and we need more attention to those that are still not equal in society- like transgender folk. 